\title{
Peer Reports of Adaptive Behavior in Twins and Singletons: Is Twinship a Risk or an Advantage?
}

\author{
Lea Pulkkinen', Inka Vaalamo', Risto Hietala', Jaakko Kaprioº , and Richard J. Rose ${ }^{3}$ \\ ' Department of Psychology, University of Jyväskylä, Jyväskylä, Finland \\ ${ }^{2}$ Department of Public Health, University of Helsinki \& National Public Health Institute, Helsinki, Finland \\ ${ }^{3}$ Department of Psychology, Indiana University, Bloomington, Indiana, USA
}

\begin{abstract}
W compared twins to their gender-matched singleton classmates in peer-assessed behavioral adjustment. Our samples include 187411 - to 12-year-old Finnish twins (687 monozygotic, MZ; 610 same-sex dizygotic, SSDZ; 577 opposite-sex dizygotic, OSDZ) and their 23,200 non-twin classmates. Data were collected using a 30 -item Multidimensional Peer Nomination Inventory containing three factors and their subscales. We found twin-singleton differences: classmates rated twin girls and boys higher than gender-matched singletons in Adaptive Behaviors (constructive, compliant, and socially active behavior), and those effects were particularly evident among OSDZ twins for assessments of social interaction, popularity, and leadership. We found no evidence that individual twins differ from singletons in Externalizing (hyperactivity-impulsivity, inattention, aggression) or Internalizing Problem Behaviors (depressive symptoms, social anxiety). Nor did we find systematic differences between MZ and SSDZ twins. Among both twins and singletons, boys exceeded girls in Externalizing, and girls exceeded boys in Internalizing Problem Behaviors. Results suggest that a twinship forms a positive developmental environment for socioemotional behavior, particularly among OSDZ twins.
\end{abstract}

Twin studies have contributed greatly to our understanding of the role of genetic factors in human development. To examine the generalizability of results from twin studies to the general population, there has been increasing interest in comparisons of twin and non-twin populations. In addition, comparisons of twins and comparable non-twins provide important information on whether the twinship context is developmentally adaptive or not. We report a study focused on effects of twinship on socioemotional behavior in early adolescence, comparing peer assessments made of twins to those made of same-aged and gendermatched singleton classmates.

Growing up as a twin is biologically and psychologically different from growing up as a singleton (Rutter \& Redshaw, 1991). First, twins have lower birthweights and suffer more from various adverse factors of pregnancy and delivery than do non-twins ( $\AA$ kerman \& Fischbein, 1991; Levy et al., 1996; Lytton et al., 1987; Moilanen \& Rantakallio, 1989). Second, twins create greater demands on their parents and must share their divided attention (Moilanen \& Ebeling, 1998); among DZ twins, those enhanced parental demands are placed on mothers who, on average, are older than mothers of classmate singletons ( $\AA$ kerman \& Fischbein, 1991). Third, inter-twin relationships may be characterized by co-twin dependence and dominance-submissiveness (Moilanen \& Ebeling, 1998). Too little is known about de-identification in identical and fraternal twin pairs a process whereby twins may develop characteristics to distinguish themselves from their co-twins (McCartney et al., 1990; McHale et al., 2001).

The biological, social, and psychological differences between growing up as a twin and a singleton have been supposed, by some, to result in cognitive and socioemotional characteristics specific to twins. Most research has evaluated twin-singleton differences from a negative perspective, anticipating more maladaptive adjustment among twins. At one extreme, twinship, especially MZ twinship, was cast as a psychopathological situation, fostering vulnerability to psychopathology and deficits in cognitive and personality function (Jackson, 1960).

Empirical evidence for such a view is negligible or nonexistent. Extensively studied cognitive differences between twins and singletons are restricted to verbal ability. Twins' overall academic competence, including nonverbal ability, does not differ from that of singletons (Lytton et al., 1987), although it is well documented that twins, particularly twin boys, are more likely to be somewhat more disadvantaged in language development and in their later performance on verbal cognitive tasks than are singletons (Akerman \& Fishbein 1991; Lytton et al., 1987; Moilanen \& Rantakallio, 1989; Rutter \& Redshaw, 1991). Some consider inferior language development of twins to be caused by perinatal morbidity (Lytton et al., 1987; Moilanen \& Rantakallio, 1989). At least in childhood, MZ twins are verbally inferior to DZ twins (Åkerman \& Fishbein, 1991; Lytton et al., 1987). It has been suggested that this difference relates to intrauterine damage in MZ twins (Lytton et al., 1987). For example, MZ twins have been found to be more premature and smaller at birth than DZ twins (Loos et al., 1998). Although Lytton et al.

Address for correspondence: Lea Pulkkinen, Department of Psychology, University of Jyväskylä, P. O. Box 35 (Agora), 40351 Jyväskylä, Finland. Email: leapulkk@cc.jyu.fi 
(1987) have argued that twins overcome initial handicaps in their physical development, so that by age 9 , their height and weight were indistinguishable from those of singletons, other findings (e.g., Pietiläinen et al., 1999) show differences in height and weight, particularly between MZ boys and singletons, persist into adolescence.

Verbal differences have been attributed also to postnatal environment and family interaction specific to the twin situation (Rutter \& Redshaw, 1991). Some twins develop a private communication system that may interfere with acquisition of expected language (Bishop $\&$ Bishop, 1998). Private language, exclusive to co-twins and intended to exclude others, is infrequent (Thorpe et al., 2001) and typically of limited duration. But language deficits in twins might be associated with an increased risk of difficulties in other psychological functions (Rutter \& Redshaw, 1991). Rutter and Redshaw conclude that "the overall risk for socioemotional behavioural disturbance in twins is not much different from that found in singletons" (p. 892); yet, the assumption that increased pre- and perinatal risk among twins contributes to increased levels of behavior problems relative to singletons has gained some popularity among researchers (Gau et al., 1992; Gjone \& Nøvik, 1995). That assumption is called here "the psychopathological hypothesis". An alternative assumption is couched within the context of the favorable social environment twinship offers for development of socioemotional behavior, via interactions with, and social support of, the co-twin; that assumption is called here "the adaptive hypothesis".

No support for the psychopathological hypothesis was obtained by Lytton et al. (1987) in a small-scale follow up of 35 twin pairs from age 2 to 9; although twins at age 9 had lower verbal intelligence scores, they did not differ from singletons in teacher-rated characteristics or on an adjustment questionnaire. In fact, teachers rated twins (the means of twin pairs were used as the unit of analysis) slightly superior to singletons in peer relations. Nor was this hypothesis supported in a study of 2- to 3-year-old twins and singletons in the Netherlands (van den Oord et al., 1995), a study on psychiatric disorders in Finnish adults (Moilanen \& Rantakallio, 1989, 1990), or a Norwegian study by Gjone and Nøvik (1995).

Gjone and Nøvik (1995) used parental ratings on the Child Behavior Checklist (CBCL) to compare same-sexed twins (1832; aged 5 to 15 years) registered in the Norwegian Medical Birth Register with a general population sample from the city of Oslo and an area in Northern Norway. There was a slightly lower level of internalizing behavior among twins aged 12 to 13 years than in the general population; otherwise, results indicated few differences in the means of problem behaviors between twins and general population. Another observation was an increased variance of externalizing problems in twins. The authors assumed, consistent with their orientation toward the psychopathological hypothesis, that a biased selection of the general population sample from the urban area might explain the negligible differences found between twins and singletons: a higher proportion of the general population group came from urban areas, which may have been associated with a higher level of behavior problems compared to the twin group, which came more often from rural areas. Another explanation, based on differential response rates and favoring the adaptive hypothesis, might be plausible. The response rate of the general population sample was only $26.5 \%$ for the age group $12-13$, whereas the response rate of twins was $-2 \frac{1}{2} \times$ higher $(62.5 \%)$ in this age group. In both samples, children aged 12 years or above were encouraged to read the information and advise their parents whether they agreed to participate. Problem children in the general population may have been less likely to participate in the study than twin children, as indicated by their reduced variance for externalizing behavior compared to that found among twins. In this study, both same-sex co-twins were included in data analysis; OSDZ twins were excluded.

In contrast, Levy et al. (1996) observed a higher rate of ADHD (attention deficit-hyperactive disorder) in male Australian twins than in their siblings, and conduct disorders were over-represented in twin populations according to findings by Simonoff (1992) in the United Kingdom Further, Gau et al. (1992) reported small but consistent differences between normative data on singletons and maternal parent ratings on twins aged 12 to 16 years, both in internalizing and externalizing behaviors - twins receiving higher scores; for twins aged 6 to 11 years, differences existed in externalizing problems only. In this study (1824 twins from the Virginia Twin Registry), one twin from each pair was excluded from data analysis; results were not presented separately for males and females. One could interpret the findings as consistent with the psychopathological hypothesis. However, the response rate to the mailed questionnaire was only $44 \%$. In the normative sample used for comparison, the response rate to a door-to-door interview request, was much higher $(82.3 \%)$. Perhaps female guardians of twins were selectively responding to the research invitation, and guardians experiencing more difficulty with the twins' behaviors were relatively more inclined to report about them.

In most previous comparisons of twins and singletons, twins were not separately classified by both gender and zygosity. Most frequently, differences between monozygotic (MZ) and same-sex dizygotic (DZ) twins, collapsed on gender, have been evaluated; results include a finding that among twins referred to psychiatric treatment, both samesex and opposite-sex DZ twins received a diagnosis of conduct disorder more often than did MZ twins (Simonoff, 1992). However, Van den Oord et al. (1995) found that 3-year-old DZ twins had lower maternal ratings of oppositionality, overactivity, anxiety and sleep problems than MZ twins and singletons. These differences were at least partly attributed to the higher age of the mothers of the $\mathrm{DZ}$ twins than those of $\mathrm{MZ}$ twins. Comparisons of the similarity of MZ and SSDZ twin pairs for a trait lies at the heart of the classical twin study (Neale \& Cardon, 1992) used to estimate the genetic contribution to interindividual variability in behavior. The classical twin study relies on several assumptions, one of which is that the two types of twins represent the same base population. Support for this assumption is found if the means and variances of $M Z$ and 
SSDZ pairs do not differ. However, twin researchers have not always made this evaluation, nor considered it necessary to carry out simultaneous comparisons with singletons.

Opposite-sex DZ twins differ from MZ twins and same-sex DZ twins in their socialization experiences. OSDZ twins have more frequent interaction with, and opportunities for social imitative learning from, an opposite sex sibling than do SSDZ and MZ twins. Current evidence from non-twin families suggest sex-typed effects from an older sibling (McHale et al., 2001). In preschool children, girls and boys with an older brother were both more masculine and less feminine. An older sister made boys more feminine and girls less masculine without affecting masculinity in boys and femininity in girls (Rust et al., 2000). Studies of influence processes between the sexes among preschoolers report that boys resist influence from same-age girls, while girls are more open to influence from same-age other children of both sexes (Maccoby, 1998). Thus, postnatal socialization effects may not occur with equal likelihood from sister to brother as from brother to sister, as Koch (1966) suggested in her pioneering study.

Hormonal transfer in utero (Miller, 1994, 1998) has been suggested, as well. Miller (1998) reviewed evidence from animal and human studies that both androgenization of a female fetus and estrogenization of a male fetus are possible. Androgenization effects, which might masculinize OSDZ girls, have received more attention, given the premise that the basic mammalian pattern is female: a fetus develops as a female unless exposed to testosterone. Animal studies suggest, however, that prenatal exposure to female hormones can affect the brain, which implies "that human development may be affected by prenatal exposure to female hormones" (Miller, 1998, p. 32). Miller's conclusion is that hormone exposure affects "the organization of the brain and its ability to display male or female typical abilities and behavior" (p. 56).

Small sample studies have suggested such directional effects among OSDZ females in personality (Resnick et al., 1993), spatial ability (Cole-Harding et al., 1988), and social attitudes (Miller \& Martin, 1995). And there is suggestive evidence that OS female twins do better in mathematics, but worse in perceptual speed and school achievements, than do SS female twins (reviewed by Miller, 1998); the same review suggests that OSDZ males are higher in school achievements and lower in motor coordination than other males. These patterns follow typical male-female differences and could, of course, arise from socialization, rather than hormonal effects. With a normal sample of 3-to 8 year-old children, Henderson and Berenbaum (1997) were not able to demonstrate that OSDZ girls spend more time with boys' toys than do SSDZ girls or girls with an older brother. Nor were differences found in play preferences made by gender-matched twins from sameand opposite-sex DZ twin pairs, ages 7-12 (Rodgers et al., 1998). Similarly, Rose et al. (2002) found no evidence of either androgenization or cross-sex socialization in analyses of pubertal development (783 OSDZ females), attitudes associated with femininity (1903 OSDZ females), or recorded fertility/fecundity (4767 OSDZ females) in Finnish female twins. If there are masculinization or femininization effects, they may be trait- and age-specific, or manifested only in clinical samples, such as in girls exposed to high levels of androgen because of congenital adrenal hyperplasia (Berenbaum \& Hines, 1992).

So, firm conclusions about differences between twins and singletons, or between twins differing in zygosity and gender, are difficult to draw. There are serious constraints in some of the previous studies, including: (1) failure to consider both zygosity and gender, (2) low response rates and consequent self-selection, (3) biased comparison groups, (4) non-representative clinical populations, (5) small samples of OSDZ twins or their complete exclusion, (6) twin-singleton comparisons limited to problem behaviors while ignoring possible differences in adaptive behaviors, and (7) reliance on parental ratings for the comparison of social behavior among twins and singletons.

The present study aimed to overcome these constraints. We compared non-twins with twins who were ascertained from Finnish population-based samples (Kaprio et al., 1990); we considered both zygosity and sex of the co-twin; we formed the non-twin comparison group from all classmates of all twins in our study, and we sampled $>1000$ school classrooms across Finland; among the variables assessed, we included adaptive socioemotional behaviors, as well as externalizing and internalizing problem behaviors; finally, we used a peer nomination technique for data collection (Pulkkinen et al., 1999). The twins and their non-twin classmates were 11 to 12 years of age.

The psychopathological hypothesis, that there are more problem behaviors among twins than non-twins, has received little consistent support in the research literature, and we expected no differences between twins and nontwins in externalizing or internalizing behaviors. In contrast, in the context of "the adaptive hypothesis", we expected that twins benefit from socialization effects experienced with their co-twin, and that expected benefit to be evident in twins' receiving a higher peer-nominated level of adaptive behavior than that attributed to classmate singletons. Socialization effects are not limited to adult-child interaction (Maccoby, 2000), and twins' reciprocal interactions may differ in same-sex and opposite-sex twin pairs; accordingly, singletons were compared with twins grouped by zygosity and by sex of the co-twin, not only with twins in general. The socialization effect was expected to be found in both genders, although we assumed that males would generally exhibit more externalizing behavior than females who, in turn, would display more adaptive behavior than males - a consistent finding in the research literature (Zoccolillo, 1993). Gender differences in internalizing behavior were not expected, because our sample children were in a prepubertal period of development, when gender differences in depression are not commonly found (Hankin et al., 1998; Wichstrom, 1999; for a review, see Keenan \& Shaw, 1997).

Another goal of the study was to test the classical twin study assumption that MZ and SSDZ twins are equivalent in peer-rated levels of adaptation. Finally, it was expected that cross-sex socialization effects (or, less likely, hormonal transfer effects) might be found. Because girls are more interested in boys' games than are boys in games that are 
stereotyped as feminine (Maccoby, 1998, p. 45), we expected this effect to emerge in higher externalizing behavior among OSDZ girls than among SSDZ girls. A higher level of adaptive behavior in OSDZ boys compared to SSDZ boys would suggest cross-sex socialization effects, as well. Consequently, gender differences were assumed to be smaller among opposite-sex twins than among same-sex twins and singletons.

\section{Materials and Methods \\ Participants}

The present study was part of an ongoing Finnish twinfamily study (FinnTwin 12) of behavioral development and health habits of five consecutive and complete birth cohorts of 12-year-old twin children (Pulkkinen et al., 1999; Rose et al., 2001). All families with twins born 1983 through 1987 were identified from the nation's Central Population Registry as part of Finnish Twin Cohort studies (Kaprio et al., 1990). Of all twin families contacted across the five birth cohorts, $87 \%$ consented to participate. Permission to contact schools to carry out school-based assessments was obtained from parents in $93 \%$ of these families, and $99 \%$ of the school principals gave permission to conduct assessments at school using peer nomination techniques. Although participation rates are very high, nonparticipation may, as always, be nonrandom, but we have evaluated effects of nonparticipation and found them to be negligible (Rose et al., 2001).

From each birth cohort, a subsample (comprising about $40 \%$ of all participant twins) was chosen for intensive study. Each subsample was formed in two steps: a sample was chosen randomly from all eligible families throughout the entire country; then that random sample was enriched by adding all remaining twin pairs for whom one or both parents exceeded a cut-off score on an 11-item alcohol dependence screening test (adapted from the MalmöModified Michigan Alcoholism Screening Test, MmMAST; Kristenson \& Trell, 1982). Possible biasing effects of this enriched sampling on twin-singleton comparisons are discussed in the context of our presentation of results. Randomly-sampled twins comprise $-60 \%$ of the intensively-studied subsample.

The data for the present study consisted of peer nominations made in the school classes of twins who were in this intensively-studied subsample. Data were collected annually during a brief time window, in the early months of each year in which participant twins, in successive birth cohorts, reached age 12. Finnish children start school in the fall of the year in which they reach age 7 years. Failure to be advanced to the next grade is rare in Finnish schools, so classes are very homogeneous for pupils' age. All twins and nearly all their classmates were 11 to 12 years old.

A total of 1874 twins, 913 girls and 961 boys, participated in this study. They were divided into five zygosity groups: 344 monozygotic (MZ) girls, 343 monozygotic boys, 280 same sex dizygotic (SSDZ) girls, 330 same sex dizygotic boys, 289 opposite sex dizygotic (OSDZ) girls, and 288 opposite sex dizygotic boys. The zygosity of the twins was determined from their perceived similarity and confusability of appearance, as reported by the twins and their parents in separately mailed questionnaires. Further information for determination of zygosity was based on photographs, parental interviews, and placental information supplied by the parents. The questionnaire items have been validated against blood-typing (Sarna et al., 1978). In some cases, zygosity could not be assigned because of missing or ambiguous information; those pairs were excluded from our analyses.

In Finnish culture, twin children are usually placed in the same classroom; in this sample, both co-twins from $-90 \%$ of all participating twin pairs were in the same class. The participant twins were enrolled in 1002 different classrooms, and over the 5-year assessment period, peer nominations were conducted in each of them. The mean class size was 25 students. The studied twins had 23,200 classmates, 11,297 girls and 11,903 boys. All who attended school, on the day the peer-nomination was conducted, participated in it.

\section{Peer Nomination}

The multidimensional inventory of children's socioemotional behavior used in this study was developed for peer nomination (MPNI; the Multidimensional Peer Nomination Inventory) with parallel Teacher Rating and Parental Rating Forms (Pulkkinen et al., 1999). The MPNI included 30 items. Core items of the MPNI were developed by Pulkkinen, in the long-term Jyväskylä Longitudinal Study of Personality and Social Development (Pulkkinen, 1982, 1998), to represent a model for emotional and behavioral regulation (Pulkkinen, 1995). Items for the assessment of four behavioral types - aggressive, anxious, constructive, and compliant behavior - were included in the inventory. These behavioral types were defined in a framework model by two orthogonal dimensions: low versus high self-control of emotions and social activity versus passivity. Aggression and anxiety have in common low self-control of emotions; constructive and compliant behavior have in common high self-control of emotions. Both aggressive and constructive behaviors are socially active; anxious and compliant behaviors passive. The item content was enriched by additional items for low self-control of emotions: attention-deficit/ hyperactivity disorder and depressive symptoms (American Psychiatric Association, 1994, Diagnostic and Statistical Manual of Mental Disorders, Fourth Edition; Rutter et al., 1981; Achenbach, 1991) for the representation of externalizing and internalizing problem behaviors.

Peer nominations were made in classroom settings, under the supervision of research staff. Each pupil was given a pad containing 32 pages, corresponding to the MPNI items. Every page included the first names of all classmates, divided by gender and presented in alphabetical order. Each MPNI question (e.g., "Which of your classmates are shy with others?") was read aloud by the staff researcher, and the pupils were asked to respond, for each item, by crossing out names of up to three female and three male classmates who best fit the described behavior. The respondent was not allowed to choose his or her own name, with the exception of the first practice question. Two items were used to practice the method at the beginning ("Who are you?", and "Which of your classmates are absent from school today?"). 
Each pupil in the class received a certain number of nominations, and for each item, the nominations received by each pupil were expressed as a percentage of the maximum possible number.

\section{Variables}

Socioemotional behavior. The MPNI items are listed in an earlier publication in this journal (Pulkkinen et al., 1999). A factor analysis (principal axis method and varimax rotation) yielded three factors (Pulkkinen et al., 1999). The first factor was defined by items for three subscales: hyperactivity-impulsivity, aggressive behavior, and inattention. Items for compliant behavior loaded negatively on this factor. The first factor describes poor control over behavior which causes social problems by violating social order or other people's rights. It was identified as Behavioral problems (Pulkkinen et al., 1999), and is here named Externalizing Problem Behaviors.

The second factor was defined by items for two subscales: depressive symptoms and social anxiety. Negative loadings were obtained on the items for socially active behavior. The factor was identified as Emotional Problems (Pulkkinen et al., 1999), and is here called Internalizing Problem Behaviors.

The third factor was defined by items for three subscales: constructive behavior, compliant behavior, and socially active behavior, the latter covering leadership, popularity, and interaction with other children. The third factor describes well-adapted, resilient behavior which is characterized by strong control of behavior and emotions. It was identified as Adjustment (Pulkkinen et al., 1999), and is here named Adaptive Behaviors. It is to be noted that, although markers of weak self-control of emotions divided into two factors (Externalizing and Internalizing Problem Behaviors), the markers of strong self-control of emotions formed one factor in this context of items. Discriminations made between individuals in adaptive behaviors are more diffuse than in problem behaviors. However, a factor analysis limited to the items describing adaptive social behavior resulted in separate components for socially more active constructive behavior and socially more passive compliant behavior (Pulkkinen et al., 1999).
For data analysis, unweighted composite (mean) scores were formed for each subscale of the three factors, and summed scores of the subscales for each factor. Cronbach's alphas, obtained separately for females and males were satisfactory.

\section{Data Analysis}

The comparisons of the twins and singletons were made in peer-nominated socioemotional characteristics, separately for males and females, because it was known that there are gender differences in socioemotional behavior (Pulkkinen et al., 1999). For individual level analyses, data from one co-twin, randomly chosen from each same-sex twin pair, was combined with data from male and female twins from opposite-sex pairs; this procedure yielded a sample of 601 girls and 624 boys born 1983 to 1987, and this sample is the focus of our analysis. These twins had 11,297 female and 11,903 male classmates. This data set of 1225 individual twins and 22,200 classmates forms Data Set I, the focus for our primary analyses. Table 1 shows the distribution of these twins by zygosity groups.

Comparisons were made using $t$ test if only two groups were contrasted: twins versus singletons, females versus males, $\mathrm{MZ}$ versus $\mathrm{DZ}$ twins, and OS twins versus SS twins. Two-way, gender (males, females) $\times$ grouping $(\mathrm{MZ}, \mathrm{SSDZ}$, OSDZ, singletons) ANOVAs were computed for each scale to detect main effects and interactions of gender and grouping. Post hoc comparisons were made by Tamhane when the variances were unequal (which occurred in most cases when the means differed) and Scheffe when the variances were equal. Analyses were made using the SPSS program package.

In comparisons of all twins and all singleton classmates, made separately for boys and girls, the $\mathrm{N}$ was sufficient to detect even small $(p<.05)$ differences (power .95 for data set I). In the comparison of zygosity groups, the number of participants was smaller for MZ and SSDZ twins than for OSDZ twins, because only one twin from the same-sex pair was included in the sample. The sample sizes were sufficient for detecting average $(p<.01)$ and strong $(p<.001)$ effects (power .90 for MZ and SSDZ twins and .95 for OSDZ twins), but the sample sizes were not sufficient for detecting small effects except for OSDZ twins in Data Set I (power $=.90)$. Consequently, only differences exceeding $p<.01$ significance level were considered.

\section{Table 1}

Number of Twin and Singleton Participants; Complete Sample and Two Subsets Used in Data Analysis, after Excluding One Twin from Each SameSex Pair. I = Twins Born 1983-1987; II = Subset of Twins Born 1986-1987. For Secondary Analyses, Random Subsamples of All Singleton Classmates Were Created; the Ns for these Subsamples Are Given in the Final Column

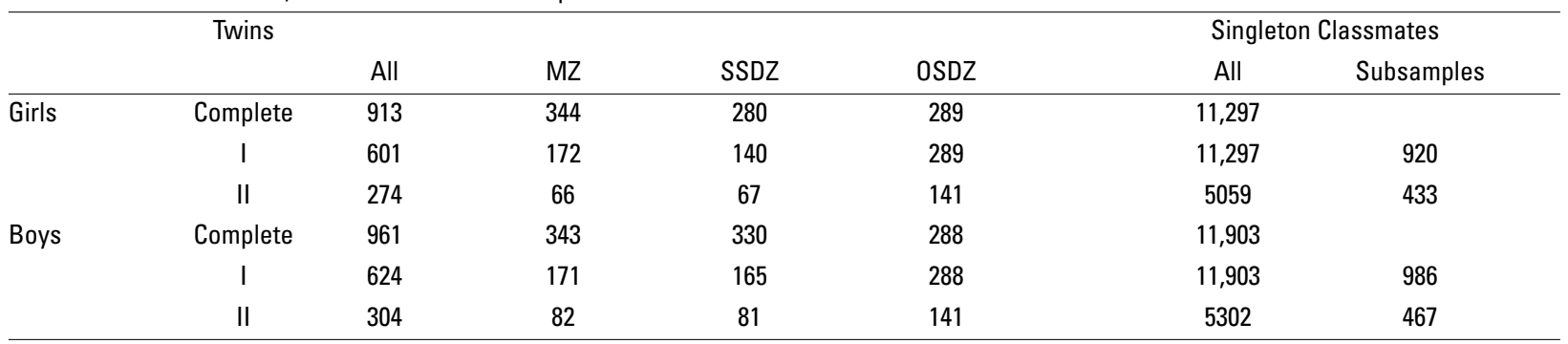




\section{Results}

Two-way gender $\times$ grouping (MZ, SSDZ, OSDZ, singletons) ANOVAs were conducted for all three factors and their subscales; all two-way ANOVAs were made with a random subsample of singleton classmates created by random sampling all non-twins in Data Set I administered the MPNI (detailed in subsequent text). The results revealed that the main effects of gender were highly significant $(p<.001)$ on all scales, except socially active behavior (consisting of leadership, popularity, and interaction with other children). There were also significant main effects of grouping. No consistent and significant $(p<.01)$ gender $\times$ grouping interactions were found.

The means and standard deviations of peer nominations for all twins, for twins grouped by zygosity, and for all singleton classmates, are presented for females in Table 2 and males in Table 3.

\section{Gender Differences}

Gender differences among twins and singletons were compared using $t$ tests (Table 4). When twins were combined across zygosity groups, gender differences were similar within samples of singletons and twins. As expected, boys displayed higher levels of peer-nominated Externalizing Problem Behaviors than did girls, and that difference was evident both among singletons and the sample of all twins collapsed on zygosity. These differences existed in all subscales, as well: hyperactivity-impulsivity, aggression, and inattention. Among twins, boys exceeded girls in Externalizing Problem Behaviors more consistently among $\mathrm{MZ}$ twins than among DZ twins. Gender differences also existed in Internalizing Problem Behaviors, with twin and singleton girls exceeding comparison groups of boys in both subscales: depressive symptoms and social anxiety. For twins, these differences were most significant and consistent among SSDZ twins. Girls were also higher in Adaptive Behaviors than boys. This difference was found in subscales for constructive and compliant behavior, but not in socially active behavior. Overall, the smallest and least consistent gender differences were obtained among OSDZ twins.

\section{Group Differences}

Twins versus singletons. When all twins (separated by gender, but combined across zygosity) were contrasted with

\section{Table 2}

Means and Standard Deviations of Peer Nominations of Female Twins and Their Singleton Female Classmates. Data Set I, from1983-1987 Cohorts

\begin{tabular}{|c|c|c|c|c|c|}
\hline Peer Nomination Scales & $\begin{array}{l}\text { All Female Twins } \\
\text { Mean }(S D)\end{array}$ & $\begin{array}{c}\text { MZF } \\
\text { Mean }(S D)\end{array}$ & $\begin{array}{c}\text { SSDZF } \\
\text { Mean }(S D)\end{array}$ & $\begin{array}{c}\text { OSDZF } \\
\text { Mean }(S D)\end{array}$ & $\begin{array}{c}\text { Female Singletons } \\
\text { Mean }(S D)\end{array}$ \\
\hline $\begin{array}{l}\text { Externalizing problem behaviors (F1) } \\
\text { Hyperactivity-impulsivity } \\
\text { Aggression } \\
\text { Inattention }\end{array}$ & $\begin{array}{l}13.35(14.59) \\
15.51(17.48) \\
13.09(13.68) \\
11.44(15.77)\end{array}$ & $\begin{array}{r}11.22(13.09) \\
12.92(15.92) \\
11.13(12.13) \\
9.63(14.33)\end{array}$ & $\begin{array}{l}13.23(13.91) \\
14.67(15.60) \\
12.68(13.53) \\
12.35(16.22)\end{array}$ & $\begin{array}{l}14.67(15.61) \\
17.46(18.99) \\
14.45(14.49) \\
12.08(16.32)\end{array}$ & $\begin{array}{l}13.84(15.84) \\
15.68(18.54) \\
12.81(14.07) \\
13.05^{c}(17.94)\end{array}$ \\
\hline $\begin{array}{l}\text { Internalizing problem behaviors (F2) } \\
\text { Depressive symptoms } \\
\text { Social anxiety }\end{array}$ & $\begin{array}{l}12.27(11.85) \\
11.68(11.04) \\
12.87(15.02)\end{array}$ & $\begin{array}{l}12.15(11.99) \\
11.25(11.35) \\
13.07(15.10)\end{array}$ & $\begin{array}{l}12.92(13.47) \\
12.46(13.11) \\
13.38(15.82)\end{array}$ & $\begin{array}{l}12.03(10.92) \\
11.57(9.71) \\
12.49(14.61)\end{array}$ & $\begin{array}{l}12.90(12.19) \\
12.38(11.82) \\
13.43(15.14)\end{array}$ \\
\hline $\begin{array}{l}\text { Adaptive behaviors (F3) } \\
\text { Constructive behavior } \\
\text { Compliant behavior } \\
\text { Socially active behavior }\end{array}$ & $\begin{array}{l}21.91(13.42) \\
21.20(16.67) \\
19.98(14.87) \\
24.56(17.65)\end{array}$ & $\begin{array}{l}20.03(12.86) \\
19.62(16.33) \\
18.89(14.54) \\
21.58(15.95)\end{array}$ & $\begin{array}{l}19.75(12.88) \\
19.30(16.58) \\
18.37(14.99) \\
21.57(16.06)\end{array}$ & $\begin{array}{l}24.08(13.71) \\
23.06(16.75) \\
21.41(14.92) \\
27.77(18.81)\end{array}$ & $\begin{array}{l}19.21^{\mathrm{a}}(12.70) \\
18.26^{\mathrm{a}}(15.80) \\
18.67^{\mathrm{c}}(13.86) \\
20.71^{\mathrm{a}}(16.63)\end{array}$ \\
\hline
\end{tabular}

Note: MZF = Monozygotic Female Twins; SSDZF = Same-Sex Dizygotic Female Twins; OSDZF = 0pposite-Sex Dizygotic Female Twins

The mean of female singletons differs from the mean of all female twins: ${ }^{a} p<.001,{ }^{b} p<.01,{ }^{c} p<.05$.

Table 3

Means and Standard Deviations of Peer Nominations of Male Twins and Their Singleton Male Classmates. Data Set I, from 1983-1987 Cohorts

\begin{tabular}{|c|c|c|c|c|c|}
\hline Peer Nomination Scales & $\begin{array}{c}\text { All Male Twins } \\
\text { Mean }(S D)\end{array}$ & $\begin{array}{c}\text { MZM } \\
\text { Mean }(S D)\end{array}$ & $\begin{array}{c}\text { SSDZM } \\
\text { Mean }(S D)\end{array}$ & $\begin{array}{c}\text { OSDZM } \\
\operatorname{Mean}(S D)\end{array}$ & $\begin{array}{c}\text { Male singletons } \\
\text { Mean }(S D)\end{array}$ \\
\hline Externalizing problem behaviors (F1) & $18.14(19.73)$ & $19.21(20.04)$ & $16.71(17.58)$ & $18.33(20.69)$ & $19.13(21.41)$ \\
\hline Hyperactivity-impulsivity & $20.17(23.06)$ & $21.03(23.86)$ & $18.89(20.99)$ & $20.40(23.74)$ & $20.56(24.03)$ \\
\hline Aggression & $16.80(17.61)$ & $17.76(17.49)$ & $15.83(16.04)$ & $16.77(18.55)$ & $17.32(18.82)$ \\
\hline Inattention & $17.46(22.27)$ & $18.81(22.95)$ & $15.41(19.99)$ & $17.84(23.08)$ & $19.50^{\circ}(24.99)$ \\
\hline Internalizing problem behaviors (F2) & $9.94(10.73)$ & $10.35(11.96)$ & 8.34 (8.75) & $10.63(10.93)$ & $10.77(11.94)$ \\
\hline Depressive symptoms & $9.67(10.48)$ & $10.18(11.50)$ & $7.80(7.50)$ & $10.44(11.19)$ & $10.70^{c}(12.02)$ \\
\hline Social anxiety & $10.21(12.67)$ & $10.49(13.68)$ & $8.88(11.54)$ & $10.82(12.66)$ & $10.84(13.68)$ \\
\hline Adaptive behaviors (F3) & $19.59(12.75)$ & $18.17(11.50)$ & $18.33(10.87)$ & $21.16(14.21)$ & $17.74 \mathrm{a}(12.94)$ \\
\hline Constructive behavior & $16.91(15.35)$ & $15.20(13.93)$ & $14.61(12.13)$ & $19.25(17.39)$ & $15.67^{c}(15.42)$ \\
\hline Compliant behavior & $17.38(14.51)$ & $15.87(14.11)$ & $15.72(12.26)$ & $19.24(15.70)$ & $17.17(15.08)$ \\
\hline Socially active behavior & $24.48(18.01)$ & $23.44(16.78)$ & $24.68(18.00)$ & $24.99(18.74)$ & 20.37 a(16.85) \\
\hline
\end{tabular}

Note: MZM = Monozygotic Male Twins; SSDZM = Same-Sex Dizygotic Male Twins; OSDZM = Opposite-Sex Dizygotic Male Twins

The mean of male singletons differs from the mean of all male twins: ${ }^{\mathrm{a}} p<.001,{ }^{\mathrm{b}} p<.01,{ }^{\mathrm{c}} p<.05$ 
Table 4

Peer Nominations of Girls (G) and Boys (B) Compared, in $t$ tests, for Singletons, All Twins, and Twins from Each Zygosity Group. Data Set l, from 1983-1987 Cohorts (See Tables 2 and 3 for Means and Standard Deviations and Table 1 for the Ns.)

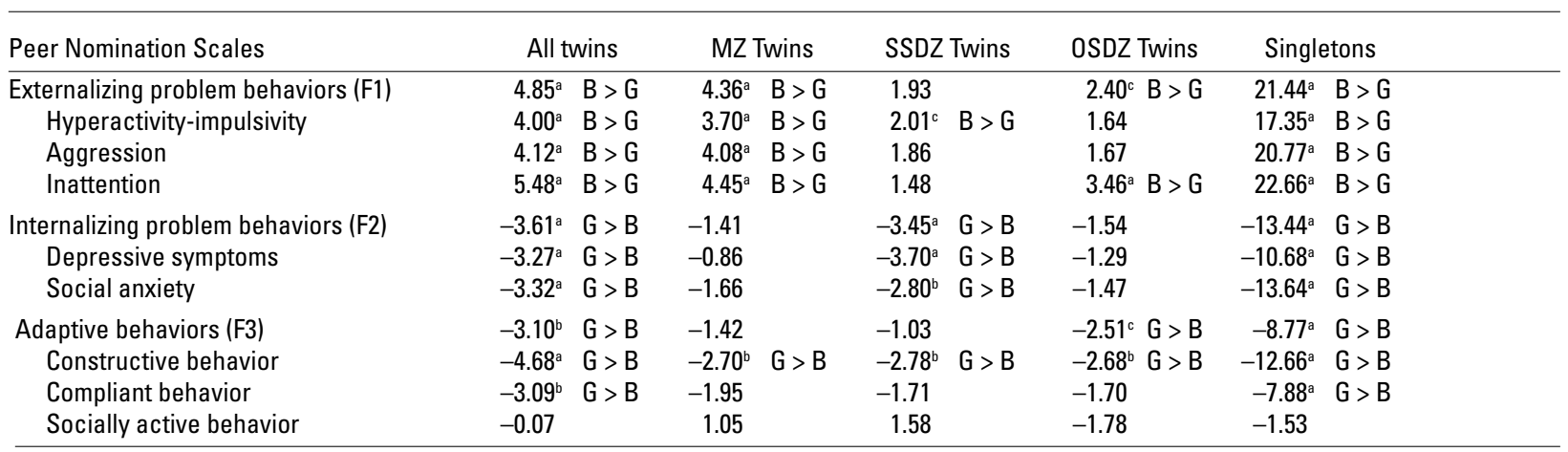

Note: ${ }^{\mathrm{a}} p<.001 .{ }^{\mathrm{b}} p<.01 .{ }^{\mathrm{c}} p<.05$.

singleton classmates, the most significant difference existed in socially active behavior. Twins exceeded singletons in sample contrasts of both females and males (Tables 2 and 3). Female twins were higher than female singletons in constructive and compliant behavior, as well, and consequently female twins exceeded female singletons in the Factor Scale of Adaptive Behaviors. Among males, twins were also given higher peer ratings than singletons in Adaptive Behaviors, a function of differences in socially active behavior. Two additional trends were obtained: male twins were lower in depressive symptoms than singletons, and male and female twins were lower in inattention than singletons.

Zygosity groups versus singletons. Main effects of grouping in the two-way gender $x$ grouping (MZ, SSDZ, OSDZ twins, and singletons) ANOVAs were revealed as group differences in socially positive behavior. Significant grouping effects were obtained for Adaptive Behaviors, $F(3,3130)=14.97, p<.001$, and for its two subscales: constructive behavior, $F(3,3130)=10.45, p<.001$ and socially active behavior $F(3,3130)=2.70, p<.044$.

One-way ANOVAs, conducted separately for females and males (Table 5) revealed several findings. First, MZ and SSDZ twins did not differ in any scale. Second, OSDZ females exceeded all other female twins and singletons in socially active behavior. Additional one-way ANOVAs on the items comprising this scale revealed that OSDZ females were rated higher than $M Z$ and SSDZ females and female singletons in leadership, and higher than female singletons also in popularity and interaction with other kids. Third, OSDZ and SSDZ males exceeded male singletons in socially active behavior. Additional one-way ANOVAs on the item level of this scale showed that SSDZ, MZ and OSDZ males were rated higher than male singletons in interaction with other kids; SSDZ and OSDZ males were rated higher than male singletons in popularity; and OSDZ males were rated higher than $M Z$ males in leadership. Fourth, OSDZ males exceeded SSDZ males in compliant behavior and both SSDZ and MZ males in constructive behavior. OSDZ males reached the mean level of females in constructive behavior (cf. Tables 2 and 3). Fifth, due to differences in subscales, OSDZ males and females were rated higher than singletons in Adaptive Behaviors. There was also a trend that OSDZ females exceeded MZ females in Externalizing Problem Behaviors and in all of its subscales. In hyperactivity-impulsivity and aggression, OSDZ females reached the male level.

\section{Table 5}

Peer Nominations of Twins Classified by Zygosity and Their Classmates Compared (in One-Way) ANOVA. Data Set I, from 1983-1987 Cohorts (See Tables 2 and 3 for Means and Standard Deviations, and Table 1 for the Ns.)

\begin{tabular}{|c|c|c|c|c|}
\hline \multirow[t]{2}{*}{ Peer Nomination Scales } & \multicolumn{2}{|c|}{ Females } & \multicolumn{2}{|c|}{ Males } \\
\hline & $\mathrm{F}$ & Post hoc & $\mathrm{F}$ & Post hoc \\
\hline $\begin{array}{l}\text { Externalizing problem behaviors (F1) } \\
\text { Hyperactivity - impulsivity } \\
\text { Aggression } \\
\text { Inattention }\end{array}$ & $\begin{array}{l}2.20 \\
2.56 \\
2.14 \\
2.37\end{array}$ & & $\begin{array}{l}0.77 \\
0.40 \\
0.48 \\
1.33\end{array}$ & \\
\hline $\begin{array}{l}\text { Internalizing problem behaviors (F2) } \\
\text { Depressive symptoms } \\
\text { Social anxiety }\end{array}$ & $\begin{array}{l}0.22 \\
0.33 \\
0.20\end{array}$ & & $\begin{array}{l}1.69 \\
2.76^{c} \\
0.89\end{array}$ & $\mathrm{~S}, 0 \mathrm{SDZ}>\mathrm{SSDZ}$ \\
\hline $\begin{array}{l}\text { Adaptive behaviors (F3) } \\
\text { Constructive behavior } \\
\text { Compliant behavior } \\
\text { Socially active behavior }\end{array}$ & $\begin{array}{r}9.79^{\mathrm{a}} \\
9.03^{\mathrm{a}} \\
3.67^{\mathrm{c}} \\
10.54^{\mathrm{a}}\end{array}$ & $\begin{array}{l}\mathrm{OSDZ}>\mathrm{S}, \mathrm{MZ}, \mathrm{SSDZ} \\
\mathrm{OSDZ}>\mathrm{S} \\
\mathrm{OSDZ}>\mathrm{S} \\
\mathrm{OSDZ}>\mathrm{S}, \mathrm{MZ}, \mathrm{SSDZ}\end{array}$ & $\begin{array}{l}5.45^{\mathrm{a}} \\
4.98 \\
2.90^{\mathrm{c}} \\
7.98^{\mathrm{a}}\end{array}$ & $\begin{array}{l}\text { OSDZ }>S \\
\text { OSDZ }>S, M Z, S S D Z \\
0 S D Z>S S D Z \\
\text { OSDZ, SSDZ }>S\end{array}$ \\
\hline
\end{tabular}

Note: ${ }^{\mathrm{a}} \mathrm{p}<.001 ;{ }^{\mathrm{b}} \mathrm{p}<.01 ;{ }^{\mathrm{c}} \mathrm{p}<.05$. 


\section{MZ and DZ Twins Contrasted}

To test a central assumption of the twin method, namely that standardized assessment of behaviors of $\mathrm{MZ}$ and $\mathrm{DZ}$ same-sex twins do not differ, peer nominations of these zygosity groups were contrasted by $t$ test, separately for each gender. The twin study assumption was confirmed. At the $p<.01$ level, there were no consistent differences between $\mathrm{MZ}$ and SSDZ females or between MZ and SSDZ males.

\section{OSDZ and SSDZ Twins Contrasted}

To test hypotheses arising from cross-sex socialization (or in utero hormonal transfer), twins from opposite-sex DZ pairs were additionally contrasted by $t$ test with gendermatched twins from same-sex DZ pairs. For females, $t$ tests revealed that OSDZ females were higher $(p<.01)$ than SSDZ females in socially active behavior. For males, the comparisons showed that OSDZ males were higher than SSDZ males in compliant and constructive behavior ( $p<.01$ for both variables) and consequently, in Adaptive Behaviors $(p=.018)$, but they did not differ in socially active behavior. Additionally, OSDZ males were higher than SSDZ males in depressive symptoms $(p=.003)$.

\section{Cautionary Comments and Secondary Analyses}

These analyses, based on our complete data (Data Set I) from twins and their non-twin classmates, suggest not only that twinship is not a risk factor for development, but intriguingly, that it may constitute an advantage. However, several cautionary comments about these analyses are necessary, and we address these in question/answer format with results obtained from a series of secondary analyses.

\section{Are these results biased by inclusion of the twins' own} peer nominations? Our procedure was designed to disguise the fact that classrooms were selected for the peer nomination exercise because they contained twin students. Accordingly, no mention was made of the fact that a given classroom included a twin or a twin pair, and twins were neither excluded from participating in peer nominations nor in being the object of nominations made by their classmates. But given that our results suggest that twins are more popular and more socially competent, a critical question is whether the results are favorably biased by permitting a twin to participate in the peer nominations and thereby nominate his or her co-twin. Twins frequently nominate their co-twins as their best classmate friend (Rose, 2002), and no doubt, attribute to their co-twins desirable behavioral characteristics. Accordingly, in the first of several secondary analyses, we excluded the twins' own peer nominations from data collected from two birth cohorts (1986 and 1987) and attempted to replicate the results reported for the full data set.

This secondary analysis (of Data Set II) was made of 578 twins (274 girls, 304 boys), and included $66 \mathrm{FMZ}$, 67 SSDZ, and $141 \mathrm{OSDZ}$ twin girls, and $82 \mathrm{MZ}$, 81 SSDZ, and 141 OSDZ twin boys. The female twins were compared to 5059 female classmates and the twin boys to 5302 classmate boys as shown in Table 1 .

The pattern of results comparing all twins and twins grouped by zygosity to sex-matched classmates is very comparable for Data Set II, the subsample in which the twins' own peer nominations are excluded (Tables 6 and 7). In contrasts of female twins to female classmates, every comparison found significant in the full sample (Data Set I, shown in Table 2), replicates in the subsample, although, given the smaller size of the subsample, significance levels are usually decreased. And, with a single exception, the same is true for the comparison of male twins to their classmates. Analyses based on the subsample from which the twins' own peer nominations are excluded, fully replicate the results on the full sample with, again, slightly reduced significance levels. The single difference in the mean of all male twins compared to all male singletons is for constructive behavior, where as shown in Table 3, singleton classmates had a lower mean in peer nominated behavior than twins with $p<.05$; that difference fails to achieve significance in the smaller subsample of Data Set II, in which nominations by the co-twin were excluded.

2. Is the twin sample biased by over-sampling for familial alcoholism risk? The questionnaire completed by twins' parents included the Malmö-Modified Michigan Alcoholism

\section{Table 6}

Means and Standard Deviations of Peer Nominations of Female Twins and Their Singleton Female Classmates. Data Set II, from1986-1987 Cohorts in which Nominations made by Twins were Excluded (See Table 1 for the Ns)

\begin{tabular}{|c|c|c|c|c|c|}
\hline Peer Nomination Scales & $\begin{array}{c}\text { All Female Twins } \\
\text { Mean }(S D)\end{array}$ & $\begin{array}{c}\text { MZF } \\
\operatorname{Mean}(S D)\end{array}$ & $\begin{array}{c}\text { SSDZF } \\
\text { Mean }(S D)\end{array}$ & $\begin{array}{c}\text { OSDZF } \\
\text { Mean }(S D)\end{array}$ & $\begin{array}{c}\text { Female Singletons } \\
\text { Mean }(S D)\end{array}$ \\
\hline Externalizing problem behaviors (F1) & $14.34(15.55)$ & $9.10(11.88)$ & $14.41(17.08)$ & $16.77(15.79)$ & $14.49(16.33)$ \\
\hline Hyperactivity-impulsivity & $16.64(18.55)$ & $10.21(14.22)$ & $15.71(18.66)$ & $20.10(19.52)$ & $16.26(18.89)$ \\
\hline Aggression & $14.34(15.10)$ & $9.50(11.83)$ & $13.46(15.90)$ & $17.03(15.56)$ & $13.52(14.77)$ \\
\hline Inattention & $12.05(15.89)$ & $7.58(12.14)$ & $14.06(19.33)$ & $13.18(15.32)$ & $13.69(18.51)$ \\
\hline Internalizing problem behaviors (F2) & $13.68(13.76)$ & $14.95(14.91)$ & $14.88(16.08)$ & $12.52(11.88)$ & $13.89(12.77)$ \\
\hline Depressive symptoms & $13.13(12.74)$ & $13.99(13.50)$ & $14.13(15.92)$ & $12.26(10.52)$ & $13.44(12.50)$ \\
\hline Social anxiety & $14.23(17.03)$ & $15.91(18.44)$ & $15.63(18.28)$ & $12.79(15.69)$ & $14.35(15.80)$ \\
\hline Adaptive behaviors (F3) & $23.38(14.43)$ & $22.42(14.56)$ & $21.45(14.08)$ & $24.74(14.49)$ & $20.04^{\mathrm{a}}(13.03)$ \\
\hline Constructive behavior & $22.09(17.83)$ & $21.91(17.78)$ & $20.29(17.81)$ & $23.03(17.93)$ & $18.91^{\mathrm{b}}(15.99)$ \\
\hline Compliant behavior & $22.11(16.25)$ & $23.88(15.84)$ & $21.62(17.03)$ & $21.53(16.12)$ & $19.55^{\mathrm{b}}(14.27)$ \\
\hline Socially active behavior & $25.93(19.14)$ & $21.48(18.04)$ & $22.44(17.26)$ & $29.67(19.84)$ & $21.66^{\mathrm{a}}(17.23)$ \\
\hline
\end{tabular}

Note: MZF = Monozygotic Female Twins; SSDZF = Same-Sex Dizygotic Female Twins; OSDZF = Opposite-Sex Dizygotic Female Twins

The mean of female singletons differs from the mean of all female twins: ${ }^{\mathrm{a}} p<.001,{ }^{\mathrm{b}} p<.01,{ }^{\mathrm{c}} p<.05$ 
Table 7

Means and Standard Deviations of Peer Nominations of Male Twins and Their Singleton Male Classmates. Data Set II, from 1986-1987 Cohorts in which Nominations made by Twins were Excluded (See Table 1 for the Ns.)

\begin{tabular}{|c|c|c|c|c|c|}
\hline Peer Nomination Scales & $\begin{array}{l}\text { All Male Twins } \\
\text { Mean }(S D)\end{array}$ & $\begin{array}{c}\text { MZM } \\
\text { Mean }(S D)\end{array}$ & $\begin{array}{c}\text { SSDZM } \\
\text { Mean }(S D)\end{array}$ & $\begin{array}{c}\text { OSDZM } \\
\text { Mean }(S D)\end{array}$ & $\begin{array}{l}\text { Male Singletons } \\
\text { Mean }(S D)\end{array}$ \\
\hline $\begin{array}{l}\text { Externalizing problem behaviors (F1) } \\
\text { Hyperactivity-impulsivity } \\
\text { Aggression } \\
\text { Inattention }\end{array}$ & $\begin{array}{l}18.56(19.87) \\
20.86(23.38) \\
17.38(18.28) \\
17.45(21.75)\end{array}$ & $\begin{array}{l}19.10(19.57) \\
21.45(23.97) \\
17.29(17.44) \\
18.54(21.17)\end{array}$ & $\begin{array}{l}17.87(17.73) \\
20.31(20.94) \\
17.57(16.43) \\
15.74(19.91)\end{array}$ & $\begin{array}{l}18.65(21.28) \\
20.82(24.48) \\
17.32(19.82) \\
17.80(23.14)\end{array}$ & $\begin{array}{l}19.81(21.86) \\
21.23(24.51) \\
17.89(19.18) \\
20.31(25.60)\end{array}$ \\
\hline $\begin{array}{l}\text { Internalizing problem behaviors (F2) } \\
\text { Depressive symptoms } \\
\text { Social anxiety }\end{array}$ & $\begin{array}{rr}10.02 & (10.42) \\
9.61 & (9.67) \\
10.43 & (12.67)\end{array}$ & $\begin{array}{l}11.06(11.94) \\
10.14(10.92) \\
11.98(14.13)\end{array}$ & $\begin{array}{l}8.02(8.51) \\
7.54(7.09) \\
8.49(11.78)\end{array}$ & $\begin{array}{l}10.60(10.38) \\
10.50(10.67) \\
10.64(12.21)\end{array}$ & $\begin{array}{l}11.72^{\mathrm{b}}(12.73) \\
11.71^{\mathrm{a}(12.88)} \\
11.72(14.50)\end{array}$ \\
\hline $\begin{array}{l}\text { Adaptive behaviors (F3) } \\
\text { Constructive behavior } \\
\text { Compliant behavior } \\
\text { Socially active behavior }\end{array}$ & $\begin{array}{l}20.42(13.06) \\
17.15(15.62) \\
18.41(15.72) \\
25.71(18.14)\end{array}$ & $\begin{array}{l}18.04(9.96) \\
13.40(11.10) \\
16.64(13.01) \\
24.07(16.41)\end{array}$ & $\begin{array}{l}18.96(10.93) \\
14.94(11.45) \\
15.47(13.35) \\
26.48(18.32)\end{array}$ & $\begin{array}{l}22.65(15.30) \\
20.59(18.94) \\
21.13(17.90) \\
26.23(19.04)\end{array}$ & $\begin{array}{l}18.40^{\mathrm{b}}(13.44) \\
16.16(15.77) \\
18.05(15.84) \\
21.00^{\mathrm{a}}(17.69)\end{array}$ \\
\hline
\end{tabular}

Note: $M Z M=$ Monozygotic Male Twins; SSDZM = Same-Sex Dizygotic Male Twins; OSDZM = Opposite-Sex Dizygotic Male Twins

The mean of male singletons differs from the mean of all male twins: ${ }^{\mathrm{a}} p<.001,{ }^{\mathrm{b}} p<.01,{ }^{\mathrm{c}} p<.05$.

Screening Test (MmMAST; Kristenson \& Trell, 1982; Seppä, 1990), augmented with two additional items to enhance its association with interview diagnoses. Sum scores of the 11 dichotomously-scored items were obtained for each mother and father. Parents' scores on the alcohol dependence screening test (MmMAST) were correlated with scores in peer nominations given to one co-twin, randomly chosen from each pair. The product moment correlations between mothers' MmMAST scores and twins' peer-nominated behaviors ranged from -0.08 (compliance and anxiety) to 0.08 (aggression and impulsivity); those between fathers and twins ranged from -0.10 (compliance) to 0.08 (impulsivity). Thus, to no surprise, there were systematic trends that parental drinking was negatively related to highly controlled compliant behavior and positively related to undercontrolled impulsive behavior in twin children. That implies that in the enriched twin sample, the means on aggression and impulsivity might tend to be higher than in the population. But, we note that, although these correlations reached statistical significance due to the large number of participants, they explained but a negligible portion of variance ( $1 \%$ or less), and sampling had little effect on twin-singleton comparisons.

3. Does maternal age explain twin-singleton differences? Prior studies have shown that parents of DZ twins are older than parents of singletons (Akerman \& Fishbein, 1991), and that maternal age is negatively related to behavioral problems (Orlebeke et al., 1998). The age of the twins' mothers was obtained from the Central Population Register and confirmed in a mailed questionnaire which the mothers filled in and returned by mail. The singletons in our study were anonymous and, therefore, the ages of their mothers were not known. However, the mean age of the mother for children born in the corresponding years of the 1980s has been recorded in Statistics Finland's official statistical tables (2001), and this was used for comparison. As expected, mean age of the mothers of our MZ twins (28.8 yrs) did not differ significantly from the mean age of mothers for all children born in the 1980 s $(28.6$ yrs;
Statistics Finland, 2001). Again as expected, mothers of our same-sex DZ twins (29.9 yrs) and mothers of our oppositesex DZ twins (30.2) were significantly (about one and half year) older than the mothers in general, and likewise, the mothers of the $\mathrm{DZ}$ twins were significantly, $F(2,2481)$ $=19.08, p=.000$, older than the mothers of MZ twins.

We estimated the effect of maternal age on children's socioemotional behavior by calculating Spearman correlations between age of the mother and one of her (randomly chosen) twin's socioemotional characteristics. No significant correlations (at the $p<.01$ level) were obtained for girls, but there was a trend for older mothers to have more compliant daughters $(.14, p<.05)$. For MZ and SSDZ males, mothers' age correlated with compliant behavior $(.20$ and .22 , respectively, $p<.01$ ). For OSDZ males, there were several significant correlations: mothers' age correlated with compliant $(.20, p=.001)$ and constructive $(.17, p=.003)$ behavior, and consequently, with Adaptive Behaviors (.16, $p=.007)$. There was also a trend that mothers' age correlated negatively with aggressive behavior $(-.15, p=.009)$ and other subscales of Externalizing Problem Behaviors $(p<.05)$. For anxiety, the correlation was positive (.14, $p=.018$ ); for depressive symptoms, it was not significant.

4. Does the extremely large singleton sample inflate singleton-twin differences? To reduce the effect of the size of the singleton sample and the influence that a large singleton sample might exert on statistical tests comparing twins to singletons, we created a random sample of singletons approximately equal in size to the sample of individual twins. The procedure was to divide the entire data into two groups, twins and their singleton classmates and then create a randomization procedure among both classmate and twin samples. The randomization was made by calculating a random variable with uniform distribution in each of these two groups, to ensure that every individual case had the same probability of being selected into the new subsamples. Among twins, this ensured that the twin retained in comparisons involving same-sex twin pairs was chosen (again) at random; among singletons, the procedure ensured that 
each classmate had an equal probability of being selected into the random subsamples. The actual composition of these randomly-generated subsamples of classmates are shown in Table 1.

The overall results, in contrast of singleton classmates with twins after controlling for inflation of the significance of findings due to the large number of singletons, is that significant contrasts were confirmed. Additionally, analyses were made in the data set restricted to twins born in 1986 and 1987 from which nominations made by the twins were excluded in order to eliminate effects from the data of the twins' own nominations. For this data set, as well, results were confirmed with a random sample of singletons, and with little change in the pattern of significant findings.

\section{Discussion}

A fundamental assumption of the classical twin study was confirmed: $\mathrm{MZ}$ and same-sex DZ twins represent the same base population. We found no significant differences between these groups of twins in peer-assessed socioemotional behavior. That is an important finding, consistent with results of self-reported personality assessments of adult twins (Johnson et al., 2002). But we did find some differences between twins and singletons, and most interestingly, these differences were consistent with the hypothesis that twinship has a positive impact on behavioral development. Most prior research has approached possible differences between twins and singletons from a psychopathological perspective, assuming that the context of twinship leads to deficits in cognitive (particularly, language) development and are associated with an increased risk in other psychological functions. Our results offer no support for this psychopathological hypothesis. There was no significant difference in any subscale, nor even any trend, showing that twins were rated higher than singletons in peer-assessed Externalizing or Internalizing Problem Behaviors. This was not an artifact of statistical power, because the sample sizes were sufficient for detecting even small differences. If there were differences, the trend was against the psychopathological hypothesis: male singletons were higher in depressive symptoms than male twins, and male and female singletons were higher than twins in inattention.

The alternative, adaptive hypothesis, was supported by evidence that twins received higher scores than singletons in Adaptive Behaviors, and particularly in the subscale, socially active behavior. Closer examination of the means of twins classified by zygosity revealed that this difference was due to OSDZ twins, who exceeded singletons in those behaviors. Had OSDZ twins not been included in the study, differences between twins and singletons would have been negligible. Our evidence that twinship may offer an adaptive context for behavioral development during childhood, a novel and perhaps surprising result, is evidence from population-based ascertainment in which brothersister twin pairs constitute nearly one-third of our studied twin sample.

The mothers of DZ twins were older than mothers of non-twins matched for birth cohort. This age difference could not, however, account for the most consistent mean difference in socioemotional behavior between the twins and singletons. That difference was in socially active behavior, for which there was no significant correlation obtained in any group or gender between maternal age and children's behavior. DZ twins, and OSDZ twins particularly, were more socially active than singletons. In OSDZ females, high leadership was the most distinctive characteristic as compared with other twins and singletons. For male twins, popularity and interaction with other kids were more characteristic than for singletons. Differences were smaller in leadership.

Leadership is generally seen as indicating dominance more typical of males than females, but in the present study, singleton boys and girls did not differ in leadership. The higher leadership skills of OSDZ females may stem from their experience with managing both their own (female) peer group (as do singletons and SS twins) and more male peers than otherwise (through interactions with their male co-twins). Differences among OSDZ females were seen in their higher scores in hyperactivity-impulsivity, aggression, inattention, and Externalizing Problem Behaviors in general compared to $\mathrm{MZ}$ females. In contrast, OSDZ males were higher than other male twins, particularly SSDZ males, in compliant and constructive behavior, as well as in depressive symptoms, which were more typical of girls than boys. The mother's age, which correlated with the son's compliant and constructive behavior, could not account for the mean differences in compliant and constructive behavior, because both the mothers of OSDZ and SSDZ males were older than the mothers of $M Z$ twins and mothers for children born in the 1980s which was used as an approximation of the age of the mothers of singletons.

Despite their different gender, OSDZ twins were much alike in the mean level of their characteristics. These results are in line with those by Rust et al. (2000) who found among siblings that having an older brother was associated with more masculine behavior in girls, and having an older sister was associated with more feminine behavior in boys.

Gender differences among singletons and all twins combined were traditional (Kavannagh \& Hops, 1994; Zoccolillo, 1993). Boys exceeded girls in Externalizing Problem Behaviors, and girls exceeded boys in Adaptive Behaviors. Unexpectedly, girls also exceeded boys in Internalizing Problem Behaviors. The participants were only 11 to 12 years old, and, therefore, gender differences were unexpected. Nolen-Hoeksema and Girgus (1994) concluded on the basis of their review that "There are no gender differences in depression rates in prepubescent children, but, after the age of 15 , girls and women are about twice as likely to be depressed as boys or men" (p. 424). In the present study, peers rated girls as displaying both more depressive symptoms and more social anxiety than boys at ages 11 to 12 . As noted by Nolen-Hoeksma and Girgus (1994), most of the prior studies of gender differences in depression and related variables have relied on the selfreports of children and adolescents. They speculate that children may not be able to assess their emotional behavior accurately, and that mothers ratings which have also been used for the assessment of depressive symptoms, may, likewise, be biased. Kessler et al. (2001) also pay attention to inconsistent symptom reports obtained from parents, 
teachers, and children. In the present study, peer nominations were used for the assessment, and gender differences appeared consistently.

Gender differences in zygosity groups suggest that twinship forms a different growing environment for OSDZ, SSDZ, and MZ twins. As noted above, gender differences were smallest among OSDZ twins. An interesting pattern of gender differences was obtained for MZ and SSDZ twins. In Externalizing Problem Behaviors, only MZ males and females differed from each other, and in the Internalizing Problem Behaviors, only SSDZ males and females differed from each other. The explanation should be sought in socialization effects, because prenatal hormonal conditions should be rather similar for $M Z$ and same-sex DZ twins. It may be possible that $M Z$ males and females, respectively, encourage similarity in their behaviors as regards aggression and related behavioral problems (or lack of them) within their close and intimate interaction of twinship. The $\mathrm{MZ}$ twin pairs also give support to each other which may protect $M Z$ girls against early emotional problems. Among SSDZ twins, twin sisters and twin brothers, respectively, are not as much alike as among $\mathrm{MZ}$ twins. Competition and frequent encounters between twins may cause similarity in boys' and girls' externalizing behaviors. SSDZ girls may also be more vulnerable to emotional problems than $M Z$ girls, if there is less support from the co-twin. For Adaptive Behaviors, gender-typical differences were obtained in constructive behavior both among $\mathrm{MZ}$ and same-sex DZ twins.

Results of the present study should be robust, for the samples were large and participation bias modest. Compared to the two large-scale studies by Gau et al. (1992) and Gjone and Nøvik (1995), attrition among twins was smaller (in the present study $87 \%$ of the parents responded to the contact letter, and $93 \%$ of them gave the permission to conduct the assessments at school), and both same-sex and opposite-sex twins were included in the study. Participating and non-participating families did not differ in key demographic characteristics. Comparisons were made separately for each zygosity group and for males and females because both grouping (twinship and zygosity together) and gender had significant main effects on findings. There was no attrition among singletons because all classmates participated in peer nomination. Absence from school did not affect the results, since all classmates were listed in the nomination technique, although of course, the absent student did not participate in the ratings. Peer nominations were collected in over 1000 school classes around the country. Consequently, the number of singletons was very high $(23,200)$. Since the twin pairs were mostly in the same class, only one randomly selected twin was included in data analysis, and findings were controlled with a subsample in which nominations made by twins were excluded. Furthermore, peer nomination used in the present study was not biased by child rearing history, as may be true of parental ratings.

The twin sample of the present study was enriched by sampling for families on lifetime parental drinking history. Parental drinking correlated very modestly with children's externalizing behaviors and explained less than $1 \%$ of variance. Furthermore, since twins did not differ from singletons in externalizing behaviors, this effect did not affect interpretation of results. The possible effect of the mother's age on results was also controlled, but the mother's age did not explain the obtained differences as discussed above.

The positive context of twinship for the development of socioemotional behavior is much neglected in the literature. Twins, particularly male twins, were more popular among their classmates, and they interacted with other children more often than singletons even when nominations made by twins were excluded. Twinship provides opportunities for shaping, imitating, and practicing social skills. The results suggest that a twin relationship forms a positive developmental environment for socioemotional behavior, particularly in the opposite-sex twinship.

\section{Acknowledgment}

Data collection in FinnTwin12 has been supported by the National Institute on Alcohol Abuse and Alcoholism (Grants AA-09203 and AA-00145) and by grants from the Academy of Finland. This paper was prepared as a part of the project: "Human Development and Its Risk Factors" financed by the Academy of Finland (Finnish Centre of Excellence Programme, 2000-2002).

\section{References}

Åkerman, B. A., \& Fischbein, S. (1991). Twins: Are they at risk? Acta Geneticae Medicae et Gemellologiae, 40, 29-40.

Achenbach, T. M. (1991). Manual for the Child Behavior Checklist/4-18 and 1991 profile. University of Vermont, Department of Psychiatry: Burlington, VT.

American Psychiatric Association. (1994). Diagnostic and statistical manual of mental disorders (4th ed.). Washington, DC: Author.

Berenbaum, S. A., \& Hines, M. (1992). Early androgens are related to childhood sex-typed toy preferences. Psychological Science, 3, 203-206.

Bishop, D. V. M. \& Bishop, S. J. (1998). “Twin language”: A risk factor for language impairment? Journal of Speech, Language, and Hearing Research, 41, 150-160.

Cole-Harding, S., Morstad, A. L., \& Wilson, J. R. (1988). Spatial ability in members of opposite-sex twin pairs. Behavior Genetics, 18, 710 (Absract.)

Gau, J. S., Silberg, J. L., Ericson, M. T., \& Hewitt J. K. (1992). Chilhood behavior problems: A comparison of twin and non-twin samples. Acta Geneticae Medicae et Gemellologiae, $41,53-63$.

Gjone, H. \& Nøvik, T. S. (1995). Parental ratings of behaviour problems: A twin and general population comparison. Journal of Child Psychology and Psychiatry, 36, 1213-1224.

Hankin, B. L., Abramson, L. Y., Moffitt, T. E., Silva, P. A., McGee, R., \& Angell, K. E. (1998). Development of depression from preadolescence to young adulthood: Emerging gender differences in a 10-year longitudinal study. Journal of Abnormal Psychology, 107, 128-140.

Henderson, B. A., \& Berenbaum, S. A. (1997). Sex-typed play in opposite-sex twins. Developmental Psychobiology, 31, $115-123$. 
Jackson, D. D. (1960). A critique of the literature on the genetics of schizophrenia. In D. D. Jackson (Ed.), The etiology of schizophrenia (pp. 37-87), New York: Basic Books.

Johnson, W., Krueger, R. F., Bouchard Jr., T. J., \& McGue, M. (2002). The personalities of twins: Just ordinary folks. Twin Research, 5, 125-131.

Kaprio, J., Koskenvuo, M., \& Rose, R. J. (1990). Populationbased twin registries: Illustrative applications in genetic epidemiology and behavioral genetics from the Finnish Twin Cohort Study. Acta Geneticae Medicae et Gemellologiae, 39, 424-439.

Kavannagh, K., \& Hops, H. (1994). Good girls? Bad boys? Gender and development as contexts for diagnosis and treatment. Advances in Clinical Child Psychology, 16, 45-79.

Keenan, K., \& Shaw, D. (1997). Developmental and social influences on young girls early problem behavior. Psychological Bulletin, 121, 95-113.

Koch, H. L. (1966). Twins and twin relations. Chicago: University of Chicago Press.

Kessler, R. C., Avenevoli, S., \& Merikangas, K. R. (2001). Mood disorders in children and adolescents: An epidemiologic perspective. Biological Psychiatry, 49, 1002-1014.

Kristenson, H., \& Trell, E. (1982). Indicators of alcohol consumption: Comparison between a questionnaire (Mm-Mast) and serum gammaglutamyltransferase (GGT) in a health survey of middle-aged males. British Journal of Addiction, 77, 297-304

Levy, F., Hay, D., McLaughlin, M., Wood, C. \& Waldman, I. (1996). Twin-sibling differences in parental reports of ADHD, speech, reading and behaviour problems. Journal of Child Psychology and Psychiatry, 37, 569-578.

Loos, R., Derom, C., Vlientinck, R., \& Derom, R. (1998). The East Flanders Prospective Twin Survey (Belgium): A population-based register. Twin Research, 1, 167-175.

Lytton, H., Watts, D., \& Dunn, B. E. (1987). Twin-singleton differences in verbal ability: Where do they stem from? Intelligence, 11, 359-369.

Maccoby, E. E. (1998). The two sexes: Growing up apart, coming together. Harvard: The Belknap Press of Harvard University Press.

Maccoby, E. E. (2000). Perspectives on gender development. International Journal of Behavioral Development, 24, 398-406.

McCartney, K., Harris, M. J., \& Bernieri, F. (1990). Growing up and growing apart: A developmental meta-analysis of twin studies. Psychological Bulletin, 107, 226-237.

McHale, S. M., Updegraff, K. A., Helms-Erikson, H., \& Crouter, A. C. (2001). Sibling influences on gender development in middle childhood and early adolescence: A longitudinal study. Developmental Psychology, 37, 115-125.

Miller, E. M. (1994). Prenatal sex hormone transfer: A reason to study opposite-sex twins. Personality and Individual Differences, 17, 511-529.

Miller, E. M. (1998). Evidence from opposite-sex twins for the effects of prenatal sex hormones. In L. Ellis \& L. Ebertz (Eds.), Males, females, and behavior (pp. 27-57). London: Praeger.

Miller, E. M., \& Martin, N. (1995). Analysis of the effect of hormones on opposite-sex twin attitudes. Acta Geneticae Medicae et Gemellologiae, 44, 41-52.
Moilanen, I., \& Ebeling, H. (1998). To be born as a twin — risks and sequelae. International Journal of Circumpolar Health, 57, 138-147.

Moilanen, I., \& Rantakallio, P. (1989). The growth, development and education of Finnish twins: A longitudinal follow-up study in a birth cohort from pregnancy to nineteen years of age. Growth, Development \& Aging, 53, 145-150.

Moilanen, I., \& Rantakallio, P. (1990). Living habits and personality development of adolescent twins: A longitudinal follow-up study in a birth cohort from pregnancy to adolescence. Acta Geneticae Medicae et Gemellologiae, 39, 215-220.

Neale, M. C., \& Cardon, L. R. (1992). Methodology for genetic studies of twins and families. Dordrecht: Kluwer Academic Publishers.

Nolen-Hoeksema, S., \& Girgus, J. S. (1994). The emergence of gender differences in depression during adolescence. Psychological Bulletin, 115, 424-443.

Orlebeke, J. F., Knol, D. L., Boomsma, D. I., \& Verhulst, F. C. (1998). Frequency of parental report of problem behavior in children decreases with increasing maternal age at delivery. Psychological Reports, 82, 395-404.

Pietiläinen, K. H., Kaprio, J., Rissanen, A., Winter, T., Rimpelä, A., Viken, R. J., \& Rose, R. J. (1999). Distribution and heritability of BMI in Finnish adolescents aged 16y and 17y: A study of 4884 twins and 2509 singletons. International Journal of Obesity and Related Metabolism Disorders, 23, 107-115.

Pulkkinen, L. (1982). Self-control and continuity from childhood to late adolescence. In B. P. Baltes \& O. G. Brim, Jr. (Eds.), Life-span development and behavior, Vol. 4 (pp. 63-105). Orlando, FL: Academic Press.

Pulkkinen, L. (1995). Behavioral precursors to accidents and resulting physical impairment. Child Development, 66, 1660-1679.

Pulkkinen, L. (1998). Levels of longitudinal data differing in complexity and the study of continuity in personality characteristics. In R. B. Cairns, L. R. Bergman, \& J. Kagan (Eds.), Methods and models for studying the individual (pp. 161-184). Beverley Hills, CA: Sage.

Pulkkinen, L., Kaprio, J., \& Rose, R. J. (1999). Peers, teachers, and parents as assessors of the behavioural and emotional problems of twins and their adjustment: The Multidimensional Peer Nomination Inventory. Twin Research, 2, 274-285.

Resnick, S. M., Gottesman, I. I., \& McGue, M. (1993). Sensation-seeking in opposite-sex twins: An effect of prenatal hormones? Behavior Genetics, 23, 323-329.

Rose, R. J. (2002). How do adolescents select their friends? A behavior-genetic perspective. In L. Pulkkinen \& A. Caspi (Eds.), Paths to successful development (pp. 106-125). Cambridge, UK: Cambridge University Press.

Rose, R. J., Dick, D. M., Viken, R. J., Pulkkinen, L., \& Kaprio, J. (2001). Drinking or abstaining at age 14? A genetic epidemiological study. Alcoholism: Clinical and Experimental Research, 25, 1594-1604.

Rose, R. J., Kaprio, J., Winter, T., Dick, D. M., Viken, R. J., Pulkkinen, L., \& Koskenvuo, M. (2002). Femininity and fertility in sisters with twin brothers: Prenatal androgenization? Cross sex socialization? Psychological Science, 13, 263-267. 
Rutter, M., \& Redshaw, J. (1991). Annotation: Growing up as a twin: Twin-singleton differences in psychological development. Journal of Child Psychology and Psychiatry, 32, 885-895.

Rutter, M., Tizard, J., \& Whitmore, K. (Eds.). (1981), Education, health and behavior. Krieber: New York.

Rust, J., Golombok, S., Hines, M., Johnston, K., Golding, J., \& the ALSPAC Study Team (2000). The role of brothers and sisters in the gender development of preschool children. Journal of Experimental Child Psychology, 77, 292-303.

Sarna, S., Kaprio, J., Sistonen, P., \& Koskenvuo, M. (1978). Diagnosis of twin zygosity by mailed questionnaire. Human Heredity, 28, 241-254.

Seppä, K. (1990). Makrosytoosin kliininen merkitys satunnaislöydöksenä avohoidossa. [The Clinical implication of macrosytosis as a chance finding in primary health care]. Acta Universitatis Tamperensis, Series A, 294. University of Tampere, Finland.
Simonoff, E. (1992). A comparison of twins and singletons with child psychiatric disorders: An item sheet study. Journal of Child Psychology and Psychiatry, 33, 1319-1332.

Statistics Finland (2001). Statistical yearbook of Finland. Keuruu: Otava.

Thorpe, K., Greenwood, R., Eivers, A., \& Rutter, M. (2001) Prevalence and developmental course of 'secret language'. International Journal of Language and Communication Disorders, 36, 43-62.

Van den Oord, E. J. C. G., Koot, H. M., Boomsma, D. I. Verhulst, F. C., \& Orlebeke, J. F. (1995). A twin-singleton comparison of problem behaviour in 2-3-year-olds. Journal of Child Psychology and Psychiatry, 36, 449-458.

Wichstrom, L. (1999). The emergence of gender difference in depressed mood during adolescence: The role of intensified gender socialization. Developmental Psychology, 35, 232-245.

Zoccolillo, M. (1993). Gender and the development of conduct disorder. Development and Psychopathology, 5, 65-78. 